Level s of pol ychl or i nat ed di benzodi oxi ns and pol ychl or i nat ed di benzof ur ans i $\mathrm{n}$ breast $\mathrm{m} / \mathrm{k}$ sampl es from three di oxi n- cont ami nat ed hot spots of Vi et nam

\begin{tabular}{|l|l|}
\hline 著者 & $\begin{array}{l}\text { Nanh Ho Dung, Ki do Ter uhi ko, Tai Pham The, } \\
\text { Okanot o Ri e, Honna Sei j i r o, Li ang Sun Xi an, } \\
\text { Anh Le Thai, Nar uzeni Shoko, Nghi Tran Ngoc, } \\
\text { N shi j o Muneko, Nakagawa H deaki , Nhu Dang } \\
\text { Duc, Tung Dao Van, Hung Nguyen Ngoc, Son Le Ke }\end{array}$ \\
\hline $\begin{array}{l}\text { j our nal or } \\
\text { publ i cat i on t i t l e }\end{array}$ & Sci ence of the Tot al Envi ronment \\
\hline vol une & 511 \\
\hline page r ange & $416-422$ \\
\hline year & $2015-$ O4 01 \\
\hline URL & ht t p: //hdl . handl e. net /2297/40614 \\
\hline
\end{tabular}




\section{Levels of polychlorinated dibenzodioxins and polychlorinated dibenzofurans in breast milk samples from three dioxin-contaminated hotspots of Vietnam}

Ho Dung Manh ${ }^{\mathrm{a}, \mathrm{b}}$, Teruhiko Kido ${ }^{\mathrm{c} *}$, Pham The Tai ${ }^{\mathrm{d}}$, Rie Okamoto ${ }^{\mathrm{c}}$, Seijiro Honma ${ }^{\mathrm{c}}$, Sun Xian Liang ${ }^{\mathrm{a}}$, Le Thai Anh $^{\mathrm{a}}$, Shoko Maruzeni ${ }^{\mathrm{e}}$, Tran Ngoc Nghi ${ }^{\mathrm{e}}$, Muneko Nishijo ${ }^{\mathrm{e}}$, Hideaki Nakagawa ${ }^{\mathrm{e}}$, Dang Duc Nhu ${ }^{\mathrm{f}}$, Dao Van Tung $^{\mathrm{g}}$, Nguyen Ngoc Hung ${ }^{\mathrm{g}}$, and Le Ke Son ${ }^{\mathrm{h}}$

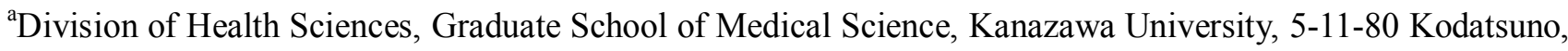
Kanazawa, Japan

${ }^{b}$ Faculty of Chemical and Environmental Engineering, Lac Hong University, No. 10 Huynh Van Nghe, Buu Long, Bien Hoa, Dong Nai, Vietnam

${ }^{c}$ Faculty of Health Sciences, Institute of Medical Pharmaceutical and Health Sciences, Kanazawa University, 5-11-80 Kodatsuno, Kanazawa, Japan

${ }^{\mathrm{d}}$ Biomedical and Pharmaceutical Research Center, Vietnam Military Medical University, Ha Noi, Vietnam

${ }^{\mathrm{e}}$ Department of Public Health, Kanazawa Medical University, 1-1 Daigaku, Uchinada, Ishikawa, Japan

${ }^{\mathrm{f} S c h o o l ~ o f ~ M e d i c i n e ~ a n d ~ P h a r m a c y, ~ V i e t n a m ~ N a t i o n a l ~ U n i v e r s i t y, ~} 144$ Xuan Thuy, Cau Giay, Hanoi, Vietnam

g10-80 Division, Hanoi Medical University, No. 1 Ton That Tung, Dong Da, Hanoi, Vietnam

${ }^{h}$ Environment Administration, Ministry of Natural Resources and Environment, 67 Nguyen Du Street, Hanoi, Vietnam

*Corresponding author: Teruhiko Kido, Faculty of Health Sciences, Institute of Medical Pharmaceutical and Health Sciences, Kanazawa University, 5-11-80 Kodatsuno, Kanazawa, Japan.

Tel: +81-76-265-2565; Fax: +81-76-265-2565; Email: kido@mhs.mp.kanazawa-u.ac.jp 


\begin{abstract}
We determined polychlorinated dibenzodioxin (PCDD) and polychlorinated dibenzofuran (PCDF) levels in breast milk of 143 primiparae living around the three most dioxin-contaminated areas of Vietnam. The women sampled lived in the vicinity of former U.S. air bases at Bien Hoa $(n=51)$, Phu Cat $(n=23)$, and Da Nang $(n$ =69), which are known as dioxin hotspots. Breast milk samples from Bien Hoa City, where residents live very close to the air base, showed high levels of 2,3,7,8-tetrachlorodibenzo-p-dioxin (TCDD), with 18\% of the samples containing $>5 \mathrm{pg}$ TCDD/g lipid. However, Phu Cat residents lived far from the air base and their samples showed lower TCDD levels, with none containing $>5$ pg TCDD/g lipid. In Da Nang, TCDD levels in mothers from Thanh Khe (close to the air base, $n=43$ ) were significantly higher than those in mothers from Son Tra (far from the air base, $n=26$ ), but not other PCDD and PCDF (PCDD/F) congeners. Although TCDD levels in Bien Hoa were highest among these hotspots, levels of other PCDD/F congeners as well as the geometric mean concentration of total PCDD/F level in Bien Hoa (9.3 pg toxic equivalents [TEQ]/g lipid) was significantly lower than the level observed in Phu Cat (14.1 pg TEQ/g lipid), Thanh Khe (14.3 pg TEQ/g lipid), and Son Tra (13.9 pg TEQ/g lipid). Our findings indicated that residents living close to former U.S. air bases were exposed to elevated levels of TCDD, but not of other PCDD/F congeners.
\end{abstract}

Keywords: Agent Orange, dioxins, breast milk, Vietnamese primiparae, hotspots 


\section{Introduction}

Polychlorinated dibenzodioxins (PCDDs) and polychlorinated dibenzofurans (PCDFs) are widespread and persistent toxic chemicals in the environment. They are released into the environment through combustion or as by-products of chemical manufacturing processes. Due to their lipophilicity, they accumulate in fat tissue and enter the human body through the food chains. They can transfer from mothers to infants via breast milk and have long half-lives in the human body (Milbrath et al., 2009).

During Operation Ranch Hand (1962-1971), the U.S. army sprayed millions of liters of various herbicides in a region south of the former Demilitarized Zone at the 17th parallel in southern Vietnam. Agent Orange, a 50:50 mixture of n-butyl ester of 2,4-dichlorophenoxyacetic acid (2,4-D) and 2,4,5-trichlorophenoxyacetic $(2,4,5-\mathrm{T})$, was the most widely used herbicide. The latter compound, 2,4,5-T, was contaminated to varying degrees with 2,3,7,8-tetrachlorodibenzo-p-dioxin (TCDD), which is the most toxic congener of the dioxin group. Other herbicides were also used in Vietnam, including Agent White (2,4-D; picloram), Agent Blue (cacodylic acid), Agent Purple (2,4-D; 2,4,5-T), Agent Green (2,4,5-T), and Agent Pink (2,4,5-T) (Stellman et al., 2003).

Baughman and Meselson (1973) detected high TCDD contamination in fish collected from heavily sprayed areas in Southern Vietnam, suggesting that this compound had accumulated significantly in the food chains in sprayed areas. Breast milk samples collected in 1970 also showed an extremely high TCDD level of 1832 parts per trillion (ppt) in a sprayed area (Schecter et al., 1995). Although tropical rain, erosion, and chemical breakdown have reduced TCDD levels, this contaminant is still found at higher levels in sprayed areas than in unsprayed regions of northern Vietnam (Schecter et al. 1995; Tawara et al. 2011).

Dwernychuk et al. (2002) found elevated levels of dioxins in soil, fish, duck, pooled human blood, and breast milk in regions close to former U.S. air bases. They theorized that high dioxin concentrations remained in the soil at former U.S. air bases, where the herbicide was stored, used, and accidentally spilled (Dwernychuk et al., 2005). These areas are called dioxin hotspots, with the three most contaminated air bases located in Bien Hoa, Da Nang, and Phu Cat (Dwernychuk et al., 2006). Large numbers of 208-liter drums of Agent Orange, Agent White, and Agent Blue were recorded in Bien Hoa (98000, 45000, 16000 drums), Da Nang (52700, 29000, 5000 drums), and Phu Cat (17000, 9000, 2900 drums) (Young, 2009). The highest soil TCDD concentrations were recently reported as 259,000 ppt, 236,000 ppt, and 365,000 ppt at the Bien Hoa, Phu Cat, and Da Nang air bases, respectively (Office 33 and Hatfield Consultants, 2011); these levels are far higher than the standard for residential soil in some countries of less than $1000 \mathrm{pg}$ toxic equivalent [TEQ]/g; (U.S. Environmental Protection Agency, 2009).

The present human breast milk biomonitoring study was conducted to assess human exposure to dioxins in residents living near these hotspots. In a previous study, we found higher dioxin levels in the breast milk of mothers living around the dioxin hotspots at Da Nang and Phu Cat, as compared with other sprayed and unsprayed areas (Tai et al., 2011). In Da Nang, an inverse association between maternal dioxin exposure and the neurodevelopment of their offspring was identified, suggesting that dioxin exposure was associated with this health risk (Nishijo et al. 2014; Tai et al. 2013). Anh et al. (2014) also reported risk factors associated with 
increased breast milk dioxin levels in mothers living in the Thanh Khe district of Da Nang. In addition, Hue et al. (2014) reported high TCDD levels in mothers living in the area surrounding the Da Nang air base.

However, no recent study has investigated breast milk dioxin levels in mothers living around the Bien Hoa air base, the largest hotspot in Vietnam. Therefore, the present study measured breast milk dioxins in primipara mothers in Bien Hoa, as compared with those of primiparae living in other dioxin-contaminated areas.

\section{Materials and Methods}

\subsection{Study areas}

Figure 1 shows the locations of the dioxin hotspots investigated in the present study. The Bien Hoa air base is located in Bien Hoa City, an industrial center in Dong Nai Province with many factories producing chemicals, paper, paints, and foodstuffs. Study participants were selected from communes (Tan Phong and Trung Dung) located within $4 \mathrm{~km}$ of the Bien Hoa air base. The Phu Cat air base is located in Phu Cat district, a rural area of Binh Dinh Province with no industrial zone nearby. There was no resident living within $5 \mathrm{~km}$ from Phu Cat airbase; therefore, study participants were selected from several communes (Cat Tuong, Cat Lam, Cat Hanh, Ngo May, and Cat Trinh), which are 5-15 km from the air base. The Da Nang air base is located in Da Nang City, an urban region of the South Central Coast of Vietnam. Study participants lived either in Thanh Khe district, located within $3 \mathrm{~km}$ of the air base, or in Son Tra district, which is located further from the air base $(7-10 \mathrm{~km})$.

\subsection{Study participants}

This study was approved by the Medical Ethics Committee of Kanazawa University (Health Permission No.89). Between 2008 and 2010, a total of 143 primiparae, including 51 primiparae in Bien Hoa, 23 primiparae in Phu Cat, 43 primiparae in Thanh Khe, and 26 primiparae in Son Tra agreed to participate in this study. We explained the purpose of study and then obtained written informed consent from every participant . The women were aged between 20 and 40 years. We collected each woman's breast milk between 4 and 16 weeks after childbirth. Furthermore, we interviewed them to collect demographic data, including age, residency, education level, employment, and income.

\subsection{Dioxin analyses}

We collected 10-20 mL breast milk from each mother. Each woman washed their hands and then expressed milk into a clean paper cup. The milk was immediately transferred into chemically cleaned containers and frozen on dry ice. The samples were transported by air to Japan, and stored at $-30^{\circ} \mathrm{C}$ until analysis.

Breast milk samples were analyzed in accordance with previously reported methods (Tai et al., 2011; Tawara et al., 2011). Briefly, lipids were extracted from $10 \mathrm{~g}$ breast milk by liquid extraction and spiked with 40-80 pg of senventeen ${ }^{13} \mathrm{C}_{12}$-labeled PCDD/F congeners, as an internal standard. PCDD/Fs were purified on a multi-layer silica gel column and separated by an active carbon-dispersed silica gel column. The final sample extract was evaporated to dryness under a nitrogen stream then re-dissolved by addition of $20 \mu \mathrm{L}$ of nonane containing 40 pg of ${ }^{13} \mathrm{C}_{12}-1,2,3,4-\mathrm{TCDD}$ and ${ }^{13} \mathrm{C}_{12}-1,2,7,8$-TCDF as external standards. 
PCDD/Fs were quantified using a gas chromatograph (HP-6980, Hewlett-Packard, Palo Alto, CA) equipped with a high-resolution mass spectrometer (HRMS: JEOL MS station-JMS700). Analyses were performed in the selected ion-monitoring mode, and the resolution was maintained above 10,000. Seventeen PCDD/F congeners were calculated on a lipid basis and then converted to TEQ using the World Health Organization toxicity equivalency factors 2005 (Van den Berg et al., 2006). The recovery rate for all PCDD/F congeners typically ranged between $60 \%$ and $95 \%$. The detection limits were determined at a signal-to-noise ratio of 3 . Samples with undetectable congener concentrations were assigned a value equal to half the detection limit.

\subsection{Statistical analyses}

We used the JMP@9 software package (SAS Institute, Japan) and R Statistical Environment (R Development Core Team, 2013) to conduct statistical analyses. Dioxin concentrations were $\log _{10}$ transformed to improve normality before using statistical tests. Analysis of variance (ANOVA) was used to compare dioxin levels between hotspots, followed by Tukey's post-hoc test to identify significant differences between individual study sites. Pearson correlation was used to calculate correlations between dioxin concentration and age or residency. Finally, multiple linear regressions were used to compare dioxin levels between hotspots, after adjusting for age and residency.

\section{Results}

\subsection{Characteristics of the study participants}

Table 1 shows the demographic characteristics of the study subjects. The average age of those living in Bien Hoa (26 years) was significantly higher than that of those living in Thanh Khe or Son Tra (23 years). Bien Hoa had the shortest residency (13 years), probably because this industrial area attracts people from other regions. In contrast, Phu Cat is a rural area and most of the mothers sampled in this region had lived there since they were born. The duration of residency in Phu Cat was therefore significantly higher than that recorded in Bien Hoa and Thanh Khe. The Bien Hoa mothers reported the highest income and education levels. In Bien Hoa, $47 \%$ of the study subjects were workers. Housewives made up 56\% of the women studied in Thanh Khe and 35\% Son Tra. In Phu Cat, $17 \%$ of the women were farmers.

\subsection{PCDD/F levels in breast milk}

Table 2 shows the levels of all seventeen PCDD/F congeners and the total TEQ of PCDDs, PCDFs, and PCDD/Fs. TCDD contributed a significantly higher percentage to the total PCDD/Fs TEQ in Bien Hoa than in Thanh Khe, Son Tra, or Phu Cat. In addition, the geometric mean of TCDD levels in Bien Hoa (2.1 pg/g lipid) and Thanh Khe (2 pg/g lipid) were significantly higher than those recorded in Son Tra (1.4 pg/g lipid), although not significantly higher than those in Phu Cat (1.7 pg/g lipid). TCDD levels in these hotspots were 3-4 times higher than those in Kim Bang (range of 0-1.3 pg/g lipid), an unsprayed area in northern Vietnam (Tai et al. 2011). Most of the other PCDD/F congeners, as well as the total PCDD/F TEQ, were significantly lower in breast milk from Bien Hoa (9.3 pg TEQ/g lipid) than in breast milk from Phu Cat (14.1 pg TEQ/g lipid), Thanh Khe (14.3 pg TEQ/g lipid), and Son Tra (13.9 pg TEQ/g lipid). With the exception of TCDD, Da Nang samples showed no significant differences in the levels of other PCDD/F congeners, as compared 
between Thanh Khe and Son Tra districts.

Figure 2 shows the TCDD level in each region sampled. An elevated level of TCDD was seen in breast milk produced by Bien Hoa and Thanh Khe residents. We selected a cut-off value of $5 \mathrm{pg} / \mathrm{g}$ lipid, which is similar to the maximum level reported in industrialized countries such as Japan (mean [range] $=1.5$ [0-3.79]) (Takekuma et al., 2014), Belgium (2.3 [1.3-3.8]) (Focant et al., 2002), and Germany (1.5 [0-5.3]) (Wittsiepe et al., 2002). Nine samples (18\%) in Bien Hoa and five samples (7\%) in Thanh Khe had TCDD levels higher than this cut-off, while none of the samples from mothers in Phu Cat and only one sample (4\%) from Son Tra had TCDD levels above the cut-off. These results suggested an increased prevalence of highly exposed mothers in areas close to air bases, particularly in Bien Hoa and Thanh Khe.

\subsection{Correlation between dioxin levels, age, and residency}

Table 3 shows the Pearson correlation coefficients between breast milk dioxin levels and either age or residency. In Bien Hoa, only residency was associated with higher TCDD ( $r=0.44, p<0.01)$ and total PCDD/F TEQ levels. There was no significant correlation between dioxin levels and residency or age in Phu Cat. In samples from Thanh Khe, which is close to the Da Nang air base, TCDD level was more closely correlated with residency $(r=0.5, p<0.01)$ than with age $(r=0.33, p<0.05)$. In contrast, samples from Son Tra, which is further from Da Nang air base, only showed correlations between age and TCDD $(r=0.52, p<$ $0.01)$ or total PCDD/F TEQ levels $(r=0.73, \mathrm{p}<0.001)$.

Table 4 shows our comparison of dioxin levels between hotspots using multiple linear regressions after adjusting for residency and age. In this model, $\log _{10}$ of the dioxin concentration was the dependent variable, while age, residency, and area were independent variables. Area was a categorical variable with four levels (Bien Hoa, Thanh Khe, Son Tra, Phu Cat). Bien Hoa was chosen as the reference category since the levels of most PCDD/Fs were lower in Bien Hoa than in the other areas sampled. We found that the adjusted geometric mean TCDD concentration in Bien Hoa (2.2 pg/g lipid) was not significantly different from that found in Thanh Khe (2.1 pg/g lipid), but was significantly higher than the mean concentrations determined in Phu Cat $(1.4 \mathrm{pg} / \mathrm{g}$ lipid; $\mathrm{p}<0.05)$ and Son Tra $(1.4 \mathrm{pg} / \mathrm{g}$ lipid; $\mathrm{p}<0.01)$. In contrast, levels of most other PCDD/F congeners, as well as total PCDD/F TEQ, were lower in Bien Hoa than in the other areas. Increased TCDD levels significantly correlated with residency.

\subsection{Risk assessment for children}

To assess the level of infant dioxin exposure, we estimated the daily dioxin intake (DDI) for infants based on the formula reported by Ulaszewska et al., 2011:

$$
\text { DDI }(\text { pg TEQ/kg/day })=(\mathrm{C} * \mathrm{~V} * \mathrm{~F}) / \mathrm{W}
$$

where $\mathrm{C}$ was the dioxin concentration (pg TEQ/g fat), $\mathrm{V}$ was the daily breast milk volume consumed (estimated at $800 \mathrm{~mL}$ ), F was the mean fat content (estimated at $0.03 \mathrm{~g} / \mathrm{mL}$ ), and $\mathrm{W}$ was the average weight of the infant for the first 6 months (estimated at $5.8 \mathrm{~kg}$ ). Using these assumptions, the estimated DDI was nearly $60 \mathrm{pg}$ TEQ/kg/day in Phu Cat, Thanh Khe, and Son Tra, 40 pg TEQ/kg/day in Bien Hoa, and 20 pg $\mathrm{TEQ} / \mathrm{kg} /$ day in the unsprayed area (Kim Bang). 


\section{Discussion}

To our knowledge, few studies have compared dioxin levels in breast milk of primiparae living around dioxin hotspots in Vietnam. In Bien Hoa, mothers living close to the air base showed a high prevalence of elevated breast milk TCDD levels. In Phu Cat, mothers lived far from the air base and showed a low prevalence of TCDD elevation. Similarly, TCDD levels observed in breast milk from Da Nang mothers were significantly higher in those living close to the air base (Thanh Khe residents) than in those living farther from the air base (Son Tra residents). However, there were no differences in the levels of any other PCDD/F congeners in mothers living in Thanh Khe and Son Tra. These results suggested that residents living close to former U.S. air bases were at risk for exposure to TCDD, but not for exposure to other PCDD/F congeners.

Residents living close to former U.S. air bases were exposed to elevated levels of TCDD. Especially, the prevalence of TCDD elevation ( $>5 \mathrm{pg} / \mathrm{g}$ lipid) was higher in Bien Hoa than those in Thanh Khe, Phu Cat or Son Tra. Three mothers in Bien Hoa had TCDD levels of $>15 \mathrm{pg} / \mathrm{g}$ breast milk lipid; this was more than 30 -fold higher than the average level observed in the unsprayed Kim Bang area (range of 0-1.3 pg/g lipid), and no mother showed levels $>15 \mathrm{pg} / \mathrm{g}$ lipid in the other hotspots examined. Furthermore, the TCDD contribution to the total PCDD/F TEQ in breast milk from these mothers was $>60 \%$, suggesting very high exposure to TCDD in Bien Hoa. In Phu Cat, however, the highest TCDD concentration in breast milk was a little over $3 \mathrm{pg} / \mathrm{g}$ lipid. This may be because the residents of Phu Cat lived far from the Phu Cat air base and were not therefore exposed to TCDD to the same extent as residents of Bien Hoa or Thanh Khe. Consistent with these findings, a previous study (Office 33 and Hatfield Consultants, 2011) also reported higher TCDD levels in environmental samples collected from the Bien Hoa and Da Nang air base than those from the Phu Cat air base. These results suggested that residents were more exposed to TCDD/Agent Orange in Bien Hoa than in the other areas.

Bien Hoa and Da Nang are large cities with a high population density in the vicinity of these air bases. The TCDD levels in breast milk from mothers living close to Bien Hoa and Da Nang air bases were not only elevated, but also highly associated with residency. Previous studies found that age was an important determinant of dioxin levels (Ulaszewska et al., 2011). However, the age range of our subjects was narrow and we did not therefore expect to observe a strong correlation with dioxin concentration. The present study found that TCDD level was more correlated with residency than with age in Thanh Khe, which is located close to the Da Nang air base. Interestingly, we did not find any correlation between age and dioxin levels in Bien Hoa, but residency was highly correlated with TCDD level. The highest TCDD level (27 pg/g lipid) identified in this study was in the breast milk of a 24-year-old mother who originated from northern Vietnam and had only been living in Bien Hoa for 16 years. These results suggested that residency influenced TCDD levels more strongly than age in residents living close to air bases.

The congener profile was similar at the hotspots examined in this study. The most abundant congeners were OCDD (40-54\%), 1234678-HpCDD (7-9\%), 123478-HxCDF (6-12\%), and 1234678-HpCDF (4-10\%). The highest TEQ contribution was from 12378-PeCDD, which accounted for 30-37\% of the total PCDD/F TEQ. TCDD contributed to $23 \%$ of the total PCDD/F TEQ in Bien Hoa, while it accounted for $10-14 \%$ of the 
PCDD/F TEQ in other hotspots. The present study did not analyze polychlorinated biphenyls (PCBs). However, industrial areas may be more exposed to PCB emission and calculation of TEQ including PCBs may produce different results.

It is interesting that the levels of most PCDD/Fs as well as total PCDD/F TEQ in breast milk were significantly lower in Bien Hoa than in Da Nang (urban area) and Phu Cat (a rural area), even though Bien Hoa City is one of the most industrialized regions of Vietnam. Consistent with this finding, Schecter et al. (1991) analyzed dioxins in pooled breast milk samples and found that most of PCDD/Fs other than TCDD were higher in Da Nang than in Dong Nai (where Bien Hoa city located). Waste incineration represents a major source of dioxins (Olie et al., 1977). These findings may therefore reflect a better control of waste incineration in Bien Hoa City. Moreover, people in rural areas such as Phu Cat may be more likely to burn household garbage in their backyard, a practice that can result in exposure to PCDD/Fs (Lemieux et al., 2000). In addition, agricultural chemicals used in rural areas could be sources of dioxins. Furthermore, because residency was significantly correlated with total PCDD/F TEQ in breast milk in the hotspots, the short residency in Bien Hoa partially resulted in their low PCDD/F TEQ.

Human exposure to dioxins occurs mainly through food consumption. Schecter et al. (2001) sampled human blood from Bien Hoa residents and found high TCDD levels of 271 ppt lipid. Furthermore, food collected from local markets in Bien Hoa City showed high TCDD levels in fat samples from duck (536-550 ppt lipid), chicken (0.95-74 ppt lipid), and fish (3.2-15349 ppt lipid). These authors suggested that Bien Hoa air base was the origin of this TCDD (Schecter et al., 2003). Our current study, carried out at Bien Hoa air base nearly one decade later, showed lower TCDD levels in human breast milk as compared with those in blood samples reported by Schecter et al. (2001). The average TCDD contribution to the total PCDD/F TEQ was 23\%, and ranged from 6 to $79 \%$ in the present study, while TCDD could contribute to over $90 \%$ of total PCDD/F TEQ in samples reported by Schecter et al. (2001). However, these TCDD levels in breast milk were more elevated as compared with the other hotspots in this study, which suggested that the residents in Bien Hoa were still exposed to TCDD from the air base. Recently, Thu et al. (2014) also reported that local people were raising chickens inside the Bien Hoa air base and free-range eggs from these animals showed high TCDD levels (238 ppt lipid). In Da Nang, Minh et al. (2009) found high TCDD levels in fish and sediment samples collected from Sen lake, located inside the Da Nang air base. Hue et al. (2014) analyzed a small number of breast milk samples $(\mathrm{n}=14)$ in Thanh Khe and found high TCDD levels, with a mean of $9.5 \mathrm{ppt}$ lipid. Our study found lower TCDD levels than those reported by Hue et al. (2014), perhaps because we recruited 3-times more subjects living in a larger area of Thanh Khe. The study by Hue et al. also found that $50 \%$ of the breast milk donors reported consuming some food originating near the air base. These findings suggested that residents living close to these air bases may be exposed to TCDD through the consumption of foods originating from the bases. We did not include a food survey and this represents a limitation of the present study. Recently, Anh et al. (2014) also reported that food consumption only partially contributed to increased dioxin levels in breast milk from mothers in Thanh Khe, suggesting that long residency was the most important risk factor. However, more research will be required to clarify the TCDD exposure route for individuals living close to former U.S. air bases in Vietnam. 
In Vietnam, breast milk is the main source of nutrition for infants. High dioxin levels in breast milk indicated that these compounds could affect the development of infants exposed to them in utero and during breastfeeding. In this study, we found that infant DDI was 3-fold higher in Thanh Khe, Son Tra, and Phu Cat, and 2-fold higher in Bien Hoa than in the unsprayed area. Our recent studies have found an association between dioxin levels in breast milk, steroid hormone levels (Kido et al., 2014, Manh et al. 2013), and sister chromatid exchange (Suzuki et al., 2014) in Vietnamese mothers. Tai et al. (2013) found significantly reduced neurodevelopmental scores in 4-month-old babies with high exposure to TCDD ( $\geq 1.8 \mathrm{pg} / \mathrm{g}$ lipid) or PCDD/F TEQ ( $\geq 17.6 \mathrm{pg}$ TEQ/g lipid). In addition, Nishijo et al. (2014) reported that perinatal TCDD exposure at $\geq 3.5$ $\mathrm{pg} / \mathrm{g}$ lipid increased autistic traits in 3-year-old children; this is a similar TCDD level to that reported recently in breast milk from Seveso, Italy (Weiss et al. 2003). Therefore, these studies are necessary to clarify the effects of dioxins on child development.

Some public health intervention programs have been conducted in Bien Hoa and Da Nang hotspots to reduce dioxin exposure. These programs have improved the knowledge, attitudes, and practices of residents in order to reduce dietary dioxin exposure (Tran et al. 2013). In addition, the remediation activities supported by the Vietnamese and U.S. governments have started to decontaminate these air bases from dioxin residues (Young et al. 2007). The fact that the present study found that TCDD levels were lower than those reported in an earlier study (Schecter et al., 2001) may provide evidence of the beneficial effects of these programs.

\section{Conclusions}

This study compared $\mathrm{PCDD} / \mathrm{F}$ levels in breast milk of primiparae living around the three most dioxin-contaminated hotspots in Vietnam. We found that mothers living close to these dioxin hotspots were exposed to TCDD, but not to other PCDD/F congeners. In particular, residents living close to Bien Hoa and Da Nang air bases showed elevated TCDD levels. In contrast, residents in Phu Cat lived far from the air base and they were not exposed to elevated levels of TCDD. However, other PCDD/F congeners in breast milk samples from Phu Cat were significantly higher than those from Bien Hoa, even though Phu Cat is a rural area. Future studies should focus on the effects of dioxin exposure in the infant offspring of these mothers.

\section{Acknowledgements}

The study was supported by a Grant-in-Aid for Scientific Research (A) from the Japan Society for the Promotion of Science, No. 19209021. The authors declare that we have no actual or potential conflict of interest including any financial, personal or other relationships with other people or organizations.

\section{References}

Anh NT, Nishijo M, Tai PT, Maruzeni S, Morikawa Y, Anh TH, et al. Maternal risk factors associated with increased dioxin concentrations in breast milk in a hot spot of dioxin contamination in Vietnam. J Expo Sci Environ Epidemiol 2014;24:489-96. 
Baughman R, Meselson M. An analytical method for detecting TCDD (dioxin): levels of TCDD in samples from Vietnam. Environ Health Perspect 1973;5:27-35.

Dwernychuk LW, Hung TM, Boivin TG, Bruce GS, Dung PT, Son LK, et al. The Agent Orange dioxin issue in Vietnam: A manageable problem. Organohalogen compounds 2006;68:312-5.

Dwernychuk LW. Dioxin hot spots in Vietnam. Chemosphere 2005;60:998-9.

Dwernychuk LW, Cau HD, Hatfield CT, Boivin TG, Hung TM, Dung PT, et al. Dioxin reservoirs in southern Viet Nam--a legacy of Agent Orange. Chemosphere 2002;47:117-37.

Focant JF, Pirard C, Thielen C, De Pauw E. Levels and profiles of PCDDs, PCDFs and cPCBs in Belgian breast milk. Estimation of infant intake. Chemosphere 2002;48:763-70.

Hue NTM, Nam VD, Thuong NV, Huyen NT, Phuong NTH, Hung NX, et al. Determination of PCDD/Fs in breast milk of women living in the vicinities of Da Nang Agent Orange hot spot (Vietnam) and estimation of the infant's daily intake. Sci Total Environ 2014;491-492:212-8.

Kido T, Dao TV, Ho MD, Dang DN, Pham NT, Okamoto R, et al. High cortisol and cortisone levels are associated with breast milk dioxin concentrations in Vietnamese women. Eur J Endocrinol 2013;170:131-9.

Lemieux PM, Lutes CC, Abbott JA, Aldous KM. Emissions of polychlorinated dibenzo-p-dioxins and dibenzofurans from the open burning of household waste in barrels. Environ Sci Technol 2000;34:377-84.

Manh HD, Kido T, Okamoto R, Sun XL, Viet NH, Nakano M, et al. The relationship between dioxins and salivary steroid hormones in Vietnamese primiparae. Environ Health Prev Med 2013;18:221- 9

Milbrath MO, Wenger Y, Chang CW, Emond C, Garabrant D, Gillespie BW, et al. Apparent half-lives of dioxins, furans, and polychlorinated biphenyls as a function of age, body fat, smoking status, and breast-feeding. Environ Health Perspect 2009;117:417-25.

Minh NH, Boivin T, Canh PN, Son LK. Comprehensive assessment of dioxin contamination in Da Nang Airbase and its vicinities: environmental levels, human exposure and options for mitigating. Interdiscip Stud Environ Chem - Environ Res Asia 2009; pp. 21-29.

Nishijo M, Tai PT, Nakagawa H, Maruzeni S, Anh NT, Luong HV, et al. Impact of perinatal dioxin exposure on infant growth: a cross-sectional and longitudinal studies in dioxin-contaminated areas in Vietnam. PLoS One 2012;7:e40273.

Nishijo M, Pham TT, Nguyen AT, Tran NN, Nakagawa H, Hoang LV, et al. 2,3,7,8-Tetrachlorodibenzo-pdioxin in breast milk increases autistic traits of 3-year-old children in Vietnam. Mol Psychiatry 2014;19:1220 6.

Office of the National Steering Committee 33 and Hatfield Consultants, 2011. Environmental and Human Health Assessment of Dioxin Contamination at Bien Hoa Airbase, Viet Nam. Final report. http://www.hatfieldgroup.com/wp-content/uploads/AgentOrangeReports/O33_1579 /Bien\%20Hoa\%20Final\%20Full\%20Report_August\%202011.pdf 
Olie K, Vermeulen PL, Hutzinger O. Chlorodibenzo-p-dioxins and chlorodibenzofurans are trace components of fly ash and flue gas of some municipal incinerators in The Netherlands. Chemosphere 1977;6:455-9.

Schecter A, Furst P, Furst C, Papke O, Ball M, Dai LC, et al. Dioxins, dibenzofurans and selected chlorinated organic compounds in human milk and blood from Cambodia, Germany, Thailand, The USA, the USSR, and Vietnam. Chemosphere 1991;23:1903-12.

Schecter A, Dai LC, Thuy LT, Quynh HT, Minh DQ, Cau HD, et al. Agent Orange and the Vietnamese: the persistence of elevated dioxin levels in human tissues. Am J Public Health 1995;85:516-22.

Schecter A, Dai LC, Päpke O, Prange J, Constable JD, Matsuda M, et al. Recent dioxin contamination from Agent Orange in residents of a southern Vietnam city. J Occup Environ Med 2001;43:435-43.

Schecter A, Quynh HT, Pavuk M, Päpke O, Malisch R, Constable JD. Food as a source of dioxin exposure in the residents of Bien Hoa City, Vietnam. J Occup Environ Med 2003;45:781-8.

Stellman JM, Stellman SD, Christian R, Weber T, Tomasallo C.The extent and patterns of usage of Agent Orange and other herbicides in Vietnam. Nature 2003;422:681-7.

Suzuki H, Kido T, Okamoto R, Nhu DD, Nishijo M, Nakagawa H, et al. The relationship between dioxin congeners in the breast milk of Vietnamese women and sister chromatid exchange. Int $\mathrm{J}$ Mol Sci 2014;15:7485-99.

Takekuma M, Saito K, Ogawa M, Matumoto R, Kobayashi S. Levels of PCDDs, PCDFs and Co-PCBs in human milk in Saitama, Japan, and epidemiological research. Chemosphere 2004;54:127-35

Tai PT, Nishijo M, Anh NT, Maruzeni S, Nakagawa H, Luong HV, et al. Dioxin exposure in breast milk and infant neurodevelopment in Vietnam. Occup Environ Med 2013;70:656-62.

Tai PT, Nishijo M, Kido T, Nakagawa H, Maruzeni S, Naganuma R, et al. Dioxin concentrations in breast milk of Vietnamese nursing mothers: a survey four decades after the herbicide spraying. Environ Sci Technol 2011;45:6625-32.

Tawara K, Nishijo M, Maruzeni S, Nakagawa H, Kido T, Naganuma R, et al. Residual congener pattern of dioxins in human breast milk in southern Vietnam. Chemosphere 2011;84:979-86.

Hoang TT, Traag WA, Murk AJ, Hoogenboom RL. Levels of polychlorinated dibenzo-p-dioxins, dibenzofurans (PCDD/Fs) and dioxin-like PCBs in free range eggs from Vietnam, including potential health risks. Chemosphere 2014;114:268-74.

Tran TH, Nguyen NB, Le VA. New strategy toward dioxin risk reduction for local residents surrounding severe dioxin hotspots in Vietnam. Glob Health Action 2013;6:21105.

Ulaszewska MM, Zuccato E, Davoli E. PCDD/Fs and dioxin-like PCBs in human milk and estimation of infant's daily intake: a review. Chemosphere 2011;83:774-82. 
U.S. Environmental Protection Agency. 2009. Review of international soil levels for dioxin. Office of Superfund Remediation and Technology innovation Washington, D.C. http://www.epa.gov/superfund/policy/remedy/pdfs/DioxinSoilLevels-International.xls

Van den Berg M, Birnbaum LS, Denison M, De Vito M, Farland W, Feeley M, et al. The 2005 World Health Organization reevaluation of human and Mammalian toxic equivalency factors for dioxins and dioxin-like compounds. Toxicol Sci 2006;93:223-41.

Weiss J, Päpke O, Bignert A, Jensen S, Greyerz E, Agostoni C, et al. Concentrations of dioxins and other organochlorines (PCBs, DDTs, HCHs) in human milk from Seveso, Milan and a Lombardian rural area in Italy: a study performed 25 years after the heavy dioxin exposure in Seveso. Acta Paediatr 2003;92:467-72.

Wittsiepe J, Fürst P, Schrey P, Lemm F, Kraft M, Eberwein G, et al. PCDD/F and dioxin-like PCB in human blood and milk from German mothers. Chemosphere 2007;67:S286-94.

Young AL. The History, Use, Disposition and Environmental Fate of Agent Orange. New York; Springer-Verlag: 2009.

Young AL, Van Houten WJ, Andrews WB. 2nd Agent Orange and Dioxin Remediation Workshop. Hanoi, Vietnam, 18-20 June 2007. Environ Sci Pollut Res Int 2008;15:113-8. 
Table 1. Characteristics of study participants.

\begin{tabular}{|c|c|c|c|c|}
\hline & $\mathrm{BH}(51)$ & TK (43) & ST (26) & $\mathrm{PC}(23)$ \\
\hline & Mean (SD) & Mean (SD) & Mean (SD) & Mean (SD) \\
\hline Age (years) & $26(3)^{\alpha}$ & $23(4)$ & $23(4)$ & $24(3)$ \\
\hline Residency (years) & $13(11)$ & $15(10)$ & $18(10)$ & $24(3)^{\beta}$ \\
\hline \multirow[t]{2}{*}{ *Family income (millions VND) } & $4(3-6)^{\gamma}$ & $2.0(1.1-3.0)$ & $2.9(2.4-4.0)$ & $2.0(1.5-3.0)$ \\
\hline & $\mathrm{N}(\%)$ & $\mathrm{N}(\%)$ & $\mathrm{N}(\%)$ & $\mathrm{N}(\%)$ \\
\hline \multicolumn{5}{|l|}{ Education } \\
\hline$>=$ high school & $32(63)$ & $14(33)$ & $10(38)$ & $13(57)$ \\
\hline$<$ high school & $19(37)$ & $29(67)$ & $16(62)$ & $10(43)$ \\
\hline \multicolumn{5}{|l|}{ Job } \\
\hline 1 Housewife & $7(14)$ & $22(56)$ & $9(35)$ & $6(26)$ \\
\hline 2 Worker & $24(47)$ & $10(26)$ & $10(38)$ & $3(13)$ \\
\hline 3 Office & $16(31)$ & $2(5)$ & $1(4)$ & $7(30)$ \\
\hline 4 Farmer & $0(0)$ & $0(0)$ & $0(0)$ & $4(17)$ \\
\hline 5 Other & $4(8)$ & $5(13)$ & $6(23)$ & $3(13)$ \\
\hline
\end{tabular}

Abbreviations in all tables and figures: BH, Bien Hoa; TK, Thanh Khe; ST, Son Tra; PC, Phu Cat; $\alpha$ : significantly higher in $\mathrm{BH}$ than TK and $\mathrm{ST}(\mathrm{P}<0.05)$; $\beta$ : significantly higher in $\mathrm{PC}$ than $\mathrm{BH}$ and TK $(\mathrm{P}<0.05) ; \gamma$ : significantly higher in $\mathrm{BH}$ than $\mathrm{TK}, \mathrm{ST}$ and $\mathrm{PC}(\mathrm{P}<0.05)$. *Median (inter-quartile range) 
Table 2. Dioxin levels in breast milk of primiparae in the hotspots

\begin{tabular}{|c|c|c|c|c|c|c|c|c|}
\hline \multirow[b]{2}{*}{$\mathrm{Pg} / \mathrm{g}$ lipid } & \multicolumn{2}{|c|}{$\mathrm{BH}(51)$} & \multicolumn{2}{|c|}{ TK (43) } & \multicolumn{2}{|c|}{ ST (26) } & \multicolumn{2}{|c|}{$\mathrm{PC}(23)$} \\
\hline & Geomean & Range & Geomean & Range & Geomean & Range & Geomean & Range \\
\hline 2378-TeCDD & 2.1 & $0-27$ & 2.0 & $1-10$ & $1.4^{\#}$ & $0-7$ & 1.7 & $1-3$ \\
\hline 12378-PeCDD & 2.8 & $1-10$ & $4.7^{* * *}$ & $2-22$ & $4.9^{* * *}$ & $3-19$ & $5.2^{* * *}$ & $3-10$ \\
\hline 123478-HxCDD & 1.5 & $0-5$ & $2.2^{* *}$ & $1-10$ & $2.2^{* *}$ & $1-8$ & $2.3^{* *}$ & $1-5$ \\
\hline 123678-HxCDD & 4.7 & $2-22$ & $8.6^{* * *}$ & $3-51$ & $8.7^{* * *}$ & $4-26$ & $8.7^{* * *}$ & $3-17$ \\
\hline 123789-HxCDD & 1.7 & $1-7$ & $2.7^{* * *}$ & $1-9$ & $2.7^{* * *}$ & $1-8$ & $3.2^{* * *}$ & $1-6$ \\
\hline 1234678-HpCDD & 9.4 & $4-59$ & 11.3 & $2-28$ & 10.5 & $5-29$ & $14.9^{* *}$ & $6-35$ \\
\hline OCDD & 59.7 & 23-194 & 61.2 & $21-152$ & 69.5 & $34-189$ & 71.4 & $34-132$ \\
\hline 2378-TeCDF & 0.4 & $0-2$ & 0.5 & $0-2$ & 0.3 & $0-1$ & 0.6 & $0-1$ \\
\hline 12378-PeCDF & 0.5 & $0-4$ & $1.3^{* * *}$ & $0-4$ & $1.0^{* * *}$ & $0-2$ & $1.9^{* * *}$ & $0-5$ \\
\hline 23478-PeCDF & 4.3 & $2-15$ & $8.0^{* * *}$ & $3-36$ & $8.1^{* * *}$ & 4-19 & $7.4^{* * *}$ & $4-16$ \\
\hline 123478-HxCDF & 6.9 & $2-42$ & $18.3^{* * *}$ & $4-86$ & $18.9^{* * *}$ & $6-51$ & $16.7^{* * *}$ & $5-35$ \\
\hline 123678-HxCDF & 4.2 & $1-24$ & $11.0^{* * *}$ & $3-50$ & $10.7^{* * *}$ & $4-28$ & $9.7^{* * * *}$ & $4-18$ \\
\hline 123789-HxCDF & 0.4 & $0-1$ & 0.3 & $0-1$ & 0.2 & $0-1$ & 0.4 & $0-1$ \\
\hline 234678-HxCDF & 0.7 & $0-3$ & $1.4^{* * *}$ & $0-4$ & $1.2^{* * *}$ & $0-3$ & $1.6^{* * *}$ & $1-3$ \\
\hline 1234678-HpCDF & 4.7 & $2-37$ & $12.8^{* * *}$ & $3-55$ & $11.5^{* * *}$ & $4-43$ & $16.4^{* * *}$ & $5-44$ \\
\hline 1234789-HpCDF & 0.7 & $0-5$ & $1.5^{* * *}$ & $0-4$ & $1.0^{*}$ & $0-5$ & $1.7^{* * *}$ & $0-5$ \\
\hline OCDF & 0.6 & $0-2$ & 0.6 & $0-5$ & 0.5 & $0-2$ & 1.0 & $0-8$ \\
\hline Total TEQ PCDDs & 6.3 & $2-32$ & $8.3^{*}$ & 3-39 & 7.9 & $4-31$ & 8.5 & $4-15$ \\
\hline Total TEQ PCDFs & 2.7 & $1-10$ & $5.8^{* * *}$ & $2-26$ & $5.8^{* * *}$ & $2-12$ & $5.4^{* * *}$ & $3-10$ \\
\hline Total TEQ PCDD/Fs & 9.3 & $3-35$ & $14.3^{* * *}$ & $5-65$ & $13.9^{* *}$ & $8-42$ & $14.1^{* *}$ & $7-24$ \\
\hline
\end{tabular}

\#: significantly higher in $\mathrm{BH}$ and TK than $\mathrm{ST}$; *: significantly higher than $\mathrm{BH}(\mathrm{P}<0.05)$; **: significantly higher than $\mathrm{BH}(\mathrm{P}<0.01)$; ***: significantly higher than $\mathrm{BH}(\mathrm{P}<0.001)$ 
Table 3. Pearson correlation between dioxin levels in breast milk and age, residency

\begin{tabular}{|c|c|c|c|c|c|c|c|c|}
\hline & \multicolumn{2}{|c|}{$\mathrm{BH}(51)$} & \multicolumn{2}{|c|}{ TK (43) } & \multicolumn{2}{|c|}{ ST (26) } & \multicolumn{2}{|c|}{$\mathrm{PC}(23)$} \\
\hline & Residency & age & Residency & age & Residency & age & Residency & age \\
\hline 2,3,7,8-TeCDD & $0.44 * *$ & -0.04 & $0.5^{* *}$ & $0.33 *$ & 0.28 & $0.52 * *$ & 0.23 & 0.30 \\
\hline 1,2,3,7,8-PeCDD & $0.45^{* * *}$ & 0.04 & $0.48 * *$ & $0.48 * *$ & $0.42 *$ & $0.7 * * *$ & 0.30 & 0.35 \\
\hline 1,2,3,4,7,8-HxCDD & $0.31^{*}$ & 0.07 & $0.39 *$ & $0.5^{* * *}$ & 0.19 & $0.63^{* * *}$ & 0.19 & 0.23 \\
\hline 1,2,3,6,7,8-HxCDD & $0.41 * *$ & 0.03 & $0.45 * *$ & $0.44 * *$ & $0.57 * *$ & $0.68^{* * *}$ & 0.13 & 0.17 \\
\hline 1,2,3,7,8,9-HxCDD & 0.24 & 0.01 & 0.31 & 0.28 & 0.20 & $0.52 * *$ & 0.04 & 0.04 \\
\hline $1,2,3,4,6,7,8-\mathrm{HpCDD}$ & 0.18 & -0.04 & 0.29 & 0.25 & 0.13 & $0.52 * *$ & 0.03 & 0.07 \\
\hline OCDD & 0.18 & 0.04 & $0.4^{*}$ & 0.21 & $0.38 *$ & $0.5^{* *}$ & -0.11 & -0.05 \\
\hline $2,3,7,8-\mathrm{TeCDF}$ & -0.01 & 0.18 & 0.26 & -0.07 & -0.04 & 0.18 & 0.10 & 0.09 \\
\hline 1,2,3,7,8-PeCDF & -0.18 & -0.16 & $0.33 *$ & 0.11 & -0.06 & 0.29 & -0.04 & -0.09 \\
\hline 2,3,4,7,8-PeCDF & -0.02 & 0.04 & $0.44 * *$ & $0.48 * *$ & 0.34 & $0.65 * * *$ & 0.27 & 0.30 \\
\hline 1,2,3,4,7,8-HxCDF & 0.05 & -0.12 & $0.42 * *$ & 0.24 & 0.16 & $0.51^{* *}$ & 0.07 & 0.02 \\
\hline $1,2,3,6,7,8-\mathrm{HxCDF}$ & -0.01 & -0.13 & $0.42 * *$ & 0.20 & 0.24 & $0.52 * *$ & 0.07 & 0.04 \\
\hline 1,2,3,7,8,9-HxCDF & $-0.36^{* *}$ & -0.11 & 0.02 & 0.13 & -0.15 & 0.37 & -0.09 & -0.09 \\
\hline 2,3,4,6,7,8-HxCDF & -0.01 & -0.04 & 0.17 & 0.28 & -0.03 & $0.5^{* *}$ & -0.06 & -0.06 \\
\hline 1,2,3,4,6,7,8-HpCDF & -0.04 & -0.20 & $0.34^{*}$ & 0.16 & -0.04 & 0.34 & -0.09 & -0.15 \\
\hline 1,2,3,4,7,8,9-HpCDF & -0.14 & -0.24 & 0.29 & -0.13 & -0.15 & 0.20 & -0.08 & -0.15 \\
\hline OCDF & $-0.38^{* *}$ & -0.12 & -0.05 & 0.25 & 0.27 & 0.21 & -0.05 & -0.13 \\
\hline Total TEQ PCDDs & $0.45^{* * *}$ & -0.04 & $0.5^{* *}$ & $0.45^{* *}$ & $0.42 *$ & $0.73 * * *$ & 0.26 & 0.31 \\
\hline Total TEQ PCDFs & -0.04 & -0.07 & $0.43 * *$ & $0.32 *$ & 0.24 & $0.59 * *$ & 0.11 & 0.09 \\
\hline Total TEQ PCDD/Fs & $0.35^{*}$ & -0.07 & $0.48 * *$ & $0.42 * *$ & 0.37 & $0.73^{* * *}$ & 0.21 & 0.23 \\
\hline
\end{tabular}

$*: \mathrm{p}<0.05, * * \mathrm{p}<0.01, * * * \mathrm{p}<0.001$ 
Table 4. Dioxin levels in breast milk among hotspots adjusted for age and residency

\begin{tabular}{|c|c|c|c|c|c|c|c|c|c|c|c|c|}
\hline \multirow[b]{2}{*}{$\mathrm{Pg} / \mathrm{g}$ lipid } & \multirow{2}{*}{$\frac{\mathrm{BH}}{\text { adj. GM }}$} & \multicolumn{2}{|l|}{ TK } & \multicolumn{2}{|l|}{ ST } & \multicolumn{2}{|l|}{$\mathrm{PC}$} & \multicolumn{2}{|c|}{ Age } & \multicolumn{2}{|c|}{ Residency } & \multirow{2}{*}{$\mathrm{R}^{2}$} \\
\hline & & adj. GM & $\mathrm{p}$ & adj. GM & $\mathrm{p}$ & adj. GM & $\mathrm{p}$ & $\beta$ & $\mathrm{p}$ & $\beta$ & $\mathrm{p}$ & \\
\hline 2378-TeCDD & 2.2 & 2.1 & & 1.4 & $* *$ & 1.4 & $*$ & 0.11 & & 0.39 & $* * *$ & 0.2 \\
\hline 12378-PeCDD & 2.8 & 5.0 & $* * *$ & 5.0 & $* * *$ & 4.6 & $* * *$ & 0.23 & $* *$ & 0.33 & $* * *$ & 0.42 \\
\hline 123478-HxCDD & 1.5 & 2.3 & $* * *$ & 2.3 & $* * *$ & 2.2 & $* *$ & 0.3 & $* * *$ & 0.19 & $*$ & 0.27 \\
\hline 123678-HxCDD & 4.8 & 9.2 & $* * *$ & 8.8 & $* * *$ & 7.6 & $* *$ & 0.18 & $*$ & 0.34 & $* * *$ & 0.38 \\
\hline 123789-HxCDD & 1.7 & 2.8 & $* * *$ & 2.7 & $* * *$ & 3.0 & $* * *$ & 0.15 & & 0.16 & & 0.26 \\
\hline 1234678-HpCDD & 9.4 & 11.5 & & 10.7 & & 14.4 & $* *$ & 0.14 & & 0.12 & & 0.12 \\
\hline OCDD & 59.8 & 62.0 & & 70.6 & & 67.1 & & 0.16 & & 0.21 & $*$ & 0.1 \\
\hline 2378-TeCDF & 0.4 & 0.5 & & 0.3 & & 0.6 & & 0.1 & & 0.01 & & 0.16 \\
\hline $12378-\mathrm{PeCDF}$ & 0.5 & 1.3 & $* * *$ & 1.0 & $* * *$ & 1.9 & $* * *$ & 0.06 & & -0.05 & & 0.41 \\
\hline 23478-PeCDF & 4.2 & 8.4 & $* * *$ & 8.5 & $* * *$ & 7.3 & $* * *$ & 0.28 & $* * *$ & 0.08 & & 0.45 \\
\hline 123478-HxCDF & 6.9 & 18.9 & $* * *$ & 19.2 & $* * *$ & 15.9 & $* * *$ & 0.1 & & 0.11 & & 0.43 \\
\hline 123678-HxCDF & 4.2 & 11.4 & $* * *$ & 10.8 & $* * *$ & 9.3 & $* * *$ & 0.09 & & 0.11 & & 0.44 \\
\hline 123789-HxCDF & 0.3 & 0.3 & & 0.2 & & 0.4 & & 0.18 & $*$ & -0.24 & $* *$ & 0.13 \\
\hline 234678-HxCDF & 0.6 & 1.4 & $* * *$ & 1.2 & $* * *$ & 1.6 & $* * *$ & 0.17 & $*$ & -0.03 & & 0.31 \\
\hline $1234678-\mathrm{HpCDF}$ & 4.6 & 13.0 & $* * *$ & 11.6 & $* * *$ & 16.2 & $* * *$ & 0.28 & $* * *$ & 0.08 & & 0.44 \\
\hline 1234789-HpCDF & 0.7 & 1.5 & $* * *$ & 1.0 & $*$ & 1.7 & $* * *$ & -0.04 & & -0.04 & & 0.21 \\
\hline OCDF & 0.6 & 0.6 & & 0.5 & & 1.1 & & 0.16 & & -0.16 & & 0.1 \\
\hline Total TEQ PCDDs & 6.5 & 8.8 & ** & 8.0 & & 7.4 & & 0.18 & * & 0.39 & $* * *$ & 0.25 \\
\hline Total TEQ PCDFs & 2.6 & 6.0 & $* * *$ & 6.0 & $* * *$ & 5.3 & $* * *$ & 0.17 & $*$ & 0.08 & & 0.44 \\
\hline Total TEQ PCDD/Fs & 9.4 & 15.0 & $* * *$ & 14.1 & $* * *$ & 12.7 & $*$ & 0.18 & $*$ & 0.31 & $* * *$ & 0.28 \\
\hline
\end{tabular}

$*: \mathrm{p}<0.05, * * \mathrm{p}<0.01, * * * \mathrm{p}<0.001$

BH is the reference category; $\beta$ : standardized coefficient; adj. GM: adjusted geometric mean 
Figure 1. Study locations in Viet Nam

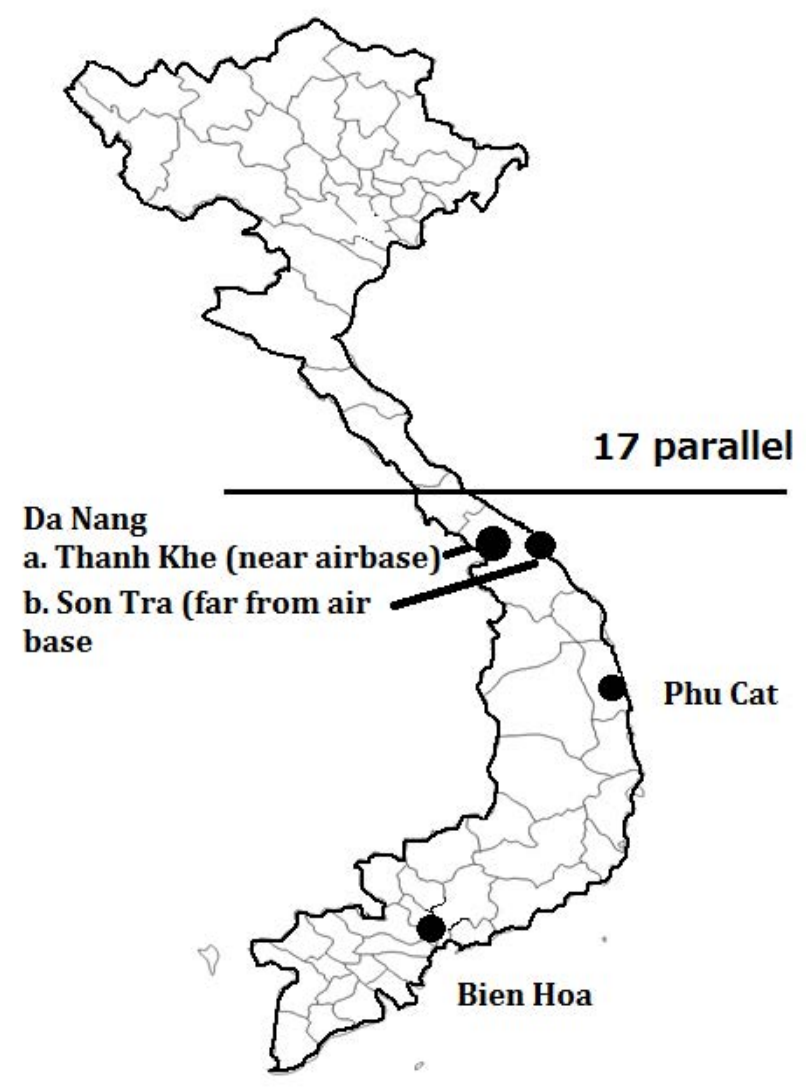


Figure 2. TCDD levels in the hotspots

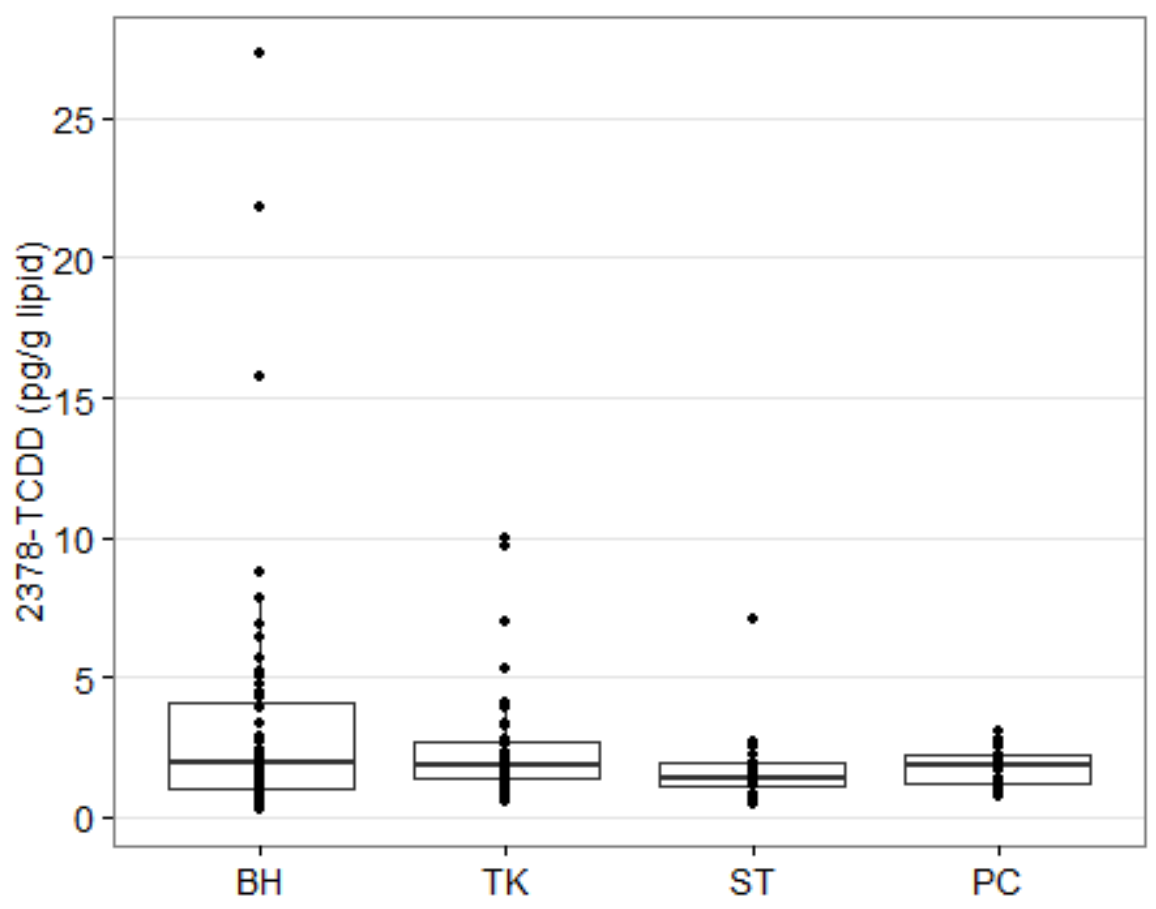

